\title{
Early nerve damage in leprosy: An electrophysiological study of ulnar and median nerves in patients with and without clinical neural deficits
}

\author{
Sajid Husain, G. N. Malaviya \\ Central Jalma Institute for Leprosy, Tajganj, Agra - 282 001, Delhi, India
}

Background: Peripheral nerve trunk involvement in leprosy is very common. However, by the time it becomes clinically manifest, the damage is quite advanced. If the preclinical nerve damage can be detected early, the deformities and disabilities can be prevented to a large extent. Aims: To assess the electrophysiological functions of the ulnar and median nerve trunks in cases of clinically manifest leprosy with and without manifest nerve damage at different durations of nerve damage. Materials and Methods: Electrophysiological functions of ulnar and median nerves were studied in leprosy patients, both normal and at different stages of disease and damage. PB cases, having disease for six months or less, without neurological symptoms and clinically normal appearing nerve. Statistical Methods: Mean was taken of different values. The changes in values of different parameters were expressed as percentage change with reference to the control values (increase or decrease). Results: Reduced nerve conduction velocities and changes in latency and amplitude were observed. Changes in sensory nerve conduction were more pronounced. Sensory latencies and amplitude changes were more severe than motor latencies and amplitudes in cases with manifest muscle palsies. Changes in MB cases were less marked. Conclusions: Further studies are needed to identify parameters likely to be helpful in the diagnosis of early nerve damage.

Key words: Humans, leprosy, neural conduction

Peripheral nerve involvement in leprosy may vary from involvement of an intradermal nerve in the cutaneous patches to a major lesion in the peripheral nerve trunk. A stage of functional blockade of conduction of nerve impulse almost always precedes visible pathological changes in the nerve. ${ }^{[1]}$ The role of electrophysiological evaluation of nerve function in the diagnosis and assessment of different neuropathies is well established. ${ }^{[2]}$ There have been few studies of motor nerve conduction in leprosy affected nerves ${ }^{[1,3-5,7-11]}$ and still fewer regarding sensory nerve conduction ${ }^{[5-6]}$ which have shown that marked slowing of conduction may occur in leprosy affected nerves. A significant decline of motor nerve conduction velocities has also been reported in clinically normal nerves in leprosy. ${ }^{[1]}$

A study was undertaken to look into the electro-physiological behavior of ulnar and median nerves trunks in the leprosy spectrum at different stages of damage with an aim to define early nerve damage. This may eventually be helpful to identify cases that are at greater risk and thereby help in the prevention of leprosyrelated disabilities and deformities.

\section{Materials and Methods}

The present study was conducted on leprosy patients attending the OPD coming for treatment. The paucibacillary (PB) and multibacillary (MB) differentiation was done as described ${ }^{[12]}$ (as they were referred from medical units). The age of the patients varied from 15 to 60 years (mean 35 years) and the majority were males (104 males and two females). They were having MDT and those with clinically manifest neural damage, were getting oral corticosteroid therapy also for varying periods at the time of their first electro-physiological evaluation.

Several of them had some complaints related to the ulnar and median nerve trunks. Of these, 75 cases had ulnar nerve and 31 median nerve involvements. The nerves were clinically involved - thickened but nontender. The pin prick pain and touch sensations (using the tip of a ball pen) were tested in the palm as described classically (three sites for the ulnar and two sites for the median nerve) to evaluate sensory functions. To assess motor functions manual muscle testing was performed and 
muscle strength graded according to the MRC scale.

Detailed physical and neurological examinations were carried out and efforts were made to identify conditions which can cause neuropathy. Detailed drug history was also obtained. Only those patients not taking any medicine other than anti-leprosy drugs and free from disease leading to neuropathies were included in the study.

The control group for the ulnar nerve (in the cubical tunnel) comprised 20 (17 males and three females) and for the median nerve (in the carpal tunnel) comprised 10 age and sex-matched healthy persons (selected at random from the staff and attendants of other cases of skin diseases attending the OPD) (three males and two females). The patients were grouped (both for ulnar and median nerve studies) as follows:

\section{A) Cases of pauci-bacillary leprosy}

a) Group 1A: Disease of six months or less; no neurological symptoms attributable to the ulnar nerve trunk and no clinical neurological deficit (17 cases).

b) Group 1B: Neurological symptoms > six months (but up to nine months); definite sensory loss in the nerve trunk innervated area and / or Muscle strength MRC Grade 3-4 (20 cases).

c) Group 1C: Neurological symptoms > nine months (but up to 12 months); definite sensory loss in the nerve trunk innervated area; Muscle strength MRC Grade 1-2 (22 cases).

\section{B) Cases of (multi-bacillary leprosy)}

Neurological symptoms (nerve pain and paracsthesia attributable to the nerve trunk involved) of $>6-12$ months duration; no clinical neurological deficit. [According to the guidelines of NLEP, cases with more than five skin lesions are taken as MB for treatment purposes in the control program. Or else the skin lesion shows bacilli on skin smear examination. It is not necessary that they have classical lepromatous features to be labeled as MB].

\section{Electrophysiological studies}

All the recordings for sensory and motor nerve conduction velocities (SNCV and MNCV) were done on a four-channel EMG machine (Neuropack-2, Nihon Kohen Corporation, Japan). The room temperatures varied around $25^{\circ} \mathrm{C}$. The patients were acclimatized during winter. The procedure was explained to the patient to reassure and have his full cooperation. Standard procedures were used as described in the accompanying manual. The tests were performed by one person $(\mathrm{SH})$ only.

The ulnar nerve was stimulated 2 to $4 \mathrm{~cm}$ above the medial epicondyle over the most superficial part of the nerve and the median nerve was stimulated in the distal wrist area where the nerve was more superficial and appeared to be most prominent on dorsiflexing the wrist. We have chosen the abductor digiti minimi in preference to the first dorsal interosseous for recording motor conduction because of its early involvement in leprosy. Sensory conduction was recorded from little finger stimulation. Abductor pollicis brevis was used for motor conduction and index finger for sensory conduction from the median nerve using surface electrodes. Supramaximal stimuli were used for all the recordings. Repeat testing was done every time under more or less similar environmental conditions.

\section{Results}

Table 1 shows the data on ulnar nerves (near the cubital tunnel) in different groups.

In Group 1A, not having any neurological deficit, 10

\begin{tabular}{lcccc}
\hline Table 1: Evaluation of electrophysiological function of the ulnar nerve in pauci-bacillary cases \\
\hline
\end{tabular}


nerves showed more or less normal motor and sensory nerve conduction velocities, latencies and amplitudes.

Seven other cases of this group had significant changes in the SNCV and MNCV, amplitudes and latencies and on subsequent follow-ups showed deterioration of nerve function. The sensory conduction was much more reduced than motor conduction and also in comparison to its control values.

In Group 1B with muscle Grade 3-4 MRC and sensory loss, SNCV and MNCV were half as compared to normal. The amplitudes were reduced and latencies enhanced.

In Group 1C, with more or less complete sensory motor loss, conduction velocities were about $20 \%$ of normal. Sensory amplitude was $46 \%$ and motor $31 \%$ of normal.
In MB cases SNCV and MNCV and amplitudes were reduced and the latencies had increased. This group had no neurological deficit [Table 2].

The median nerve affection in different groups (in the carpal tunnel) showed similar patterns of recordings both for pauci and multibaciliary groups which are shown in Tables 3 and 4 respectively.

Of the nine affected median nerve in MB cases with pain and paraesthesia (which were available for followup), two were suspected to have nerve abscess on clinical examination. In these two cases even though there was no clinical neurological deficit, the electrophysiological functions were markedly affected. Data for these cases are separately presented in Table 3.

Table 2: Preoperative evaluation of electrophysiological function of the ulnar nerve in multi-bacillary cases

\section{Electrophysiological function}

Normal (control)
20

Motor function

Mean NCV1 m/s

$\%$ change

Mean amplitude $\mathrm{mV}$

$\%$ change

Mean latency ms

$\%$ change

Sensory function

Mean NCV2 m/s

$\%$ change

Mean amplitude $\mathrm{mV}$

$\%$ change

Mean latency ms

$\%$ change

\section{Duration of disease}

\section{Cases without neurological symptoms $>6$ to 12 months. \\ These are MB cases whereas \\ Table 1 refers to PB cases}

\section{Cases with parasthesia and pain $>6$ to 12 months. These are MB cases whereas Table 1 refers to PB cases} 11

51.5

86.4

5.67

73.06

11.08 121.0

49.5

77.95

22.8

78.89

8.12

127.0

Table 3: Evaluation of electrophysiological function of the median nerve in pauci-bacillary cases

\begin{tabular}{|c|c|c|c|c|c|}
\hline \multirow{3}{*}{$\begin{array}{l}\text { Electrophysiological } \\
\text { function }\end{array}$} & \multirow{3}{*}{$\begin{array}{c}\text { Normal } \\
\text { (control) }\end{array}$} & \multicolumn{3}{|c|}{ Duration of disease } & \multirow{3}{*}{$\begin{array}{c}\text { Group 1C } \\
>\text { Nine to } 12 \text { months, } \\
\text { neurological symptoms } \\
\text { present, motor power } \\
1+\text { to } 2+\text {, anesthesia } \\
\text { present }\end{array}$} \\
\hline & & \multicolumn{2}{|c|}{ Group 1A } & \multirow{2}{*}{$\begin{array}{c}\text { Group 1B } \\
\text { More than six } \\
\text { to nine months, } \\
\text { clinical symptoms } \\
\text { present, motor } \\
\text { power } 3+\text { or more, } \\
\text { anesthesia present }\end{array}$} & \\
\hline & & $\begin{array}{l}\text { Less than six } \\
\text { months, no } \\
\text { clinical symptom, no } \\
\text { electrophysiological } \\
\text { symptom, } \\
\text { deficit }\end{array}$ & $\begin{array}{l}\text { Less than six } \\
\text { months, no } \\
\text { clinical only } \\
\text { electrophysiological } \\
\text { deficit present }\end{array}$ & & \\
\hline $\begin{array}{l}\text { No. of cases } \\
\text { Motor function }\end{array}$ & 10 & 6 & 3 & 8 & 5 \\
\hline Mean NCV1 m/s & 59.6 & 58.52 & 49.0 & 26.5 & 10.13 \\
\hline$\%$ change & 100 & 98.18 & 85.21 & 44.46 & 16.99 \\
\hline Mean amplitude $\mathrm{mV}$ & 7.76 & 7.30 & 7.5 & 3.87 & 2.16 \\
\hline$\%$ change & 100 & 94.72 & 96.64 & 49.0 & 27.84 \\
\hline Mean latency ms & 4.76 & 4.87 & 5.25 & 6.65 & 16.82 \\
\hline$\%$ change & 100 & 102.41 & 110.25 & 139.0 & 353.36 \\
\hline Sensory function & & & & & \\
\hline Mean NCV2 m/s & 59.43 & 56.35 & 45.25 & 19.4 & 12.75 \\
\hline$\%$ change & 100 & 94.81 & 76.14 & 32.64 & 21.45 \\
\hline Mean amplitude $\mathrm{mV}$ & 42.26 & 39.92 & 31.3 & 19.0 & 9.69 \\
\hline$\%$ change & 100 & 94.46 & 74.06 & 44.95 & 22.92 \\
\hline Mean latency ms & 3.85 & 3.23 & 3.57 & 5.70 & 11.5 \\
\hline$\%$ change & 100 & 105.90 & 117.0 & 148.22 & 377.49 \\
\hline
\end{tabular}


Table 4: Evaluation of electrophysiological function of the median nerve in multi-bacillary cases

\begin{tabular}{cc}
\hline Normal & Cases without \\
(control) & clinical symptoms
\end{tabular}

\section{Cases with clinical \\ symptoms for $>6$ months to 12 months}

\begin{tabular}{cc}
\hline With Pain & With nerve abscess \\
$\mathbf{7}$ & $\mathbf{2}$ \\
& \\
56.0 & 42.62 \\
93.5 & 71.5 \\
6.87 & 5.95 \\
88.53 & 76.67 \\
6.75 & 7.31 \\
141.0 & 158.83 \\
& \\
46.25 & 69.83 \\
77.82 & 41.5 \\
34.7 & 31.45 \\
82.11 & 74.06 \\
5.47 & 6.07 \\
178.46 & 198.4
\end{tabular}

\section{Discussion}

The interpretation of electrophysiological functions of nerve trunks is usually based on the analysis of three basic criteria - velocity, latency and amplitude of the evoked response. Amplitude represents a summation of activity of the axons within a nerve trunk.

It has been observed in electrophysiological studies that in a significant proportion of cases, sensory velocity is at the lower limit of normal or slightly delayed while amplitude and duration of action potential is within the normal range suggesting that leprosy results in diffuse neuropathy even at a stage where clinically it is restricted and cannot be detected by routine clinical testing. ${ }^{[8,13,14]}$ It has been observed that even though clinically normal, $16 \%$ among ulnar and $20 \%$ among median nerves were electrically abnormal in leprosy. Ghiglione et al, in a series of 282 nerves having electrophysiological abnormalities, found 123 nerves to be clinically asymptomatic. Slowing of MNCV has been observed in patients without any clinical abnormality. ${ }^{[1]}$ Reduced conduction velocities in clinically normal nerves probably represent the preclinical stage (without symptoms and signs) of damage which becomes manifest when certain defined quantum of nerve fibers becomes nonfunctional.

Several workers ${ }^{[13-16]}$ have noted that normal sensorymotor conduction velocities can be found in the diseased nerves which could be explained by involvement of certain fascicles of the affected nerve with little or insignificant involvement of others. Since nerve conduction velocity is calculated on the basis of fast conducting fibers, it may be normal if slow conducting fibers are predominantly damaged. ${ }^{[17]}$ Since damage to C and A-delta fibers precedes the involvement of A-delta fibers in leprosy, increasing damage to the $\mathrm{C}$ and $\mathrm{A}$-delta fibers is accompanied by increasing A-alfa fiber involvement. This means that a reduction of conduction velocity indicates severe damage to $A$-delta and $C$ fibers. As segmental demyelination progresses, it affects more number of fibers and conduction velocity is altered due to distorted conduction along small segments of demyelination in the majority of fibers. ${ }^{[15]}$

The sensory fibers are damaged early in leprosy and therefore show more quantum of changes in conduction velocities as compared to motor nerve fibers in the early stages of damage. However, the amplitude changes are much more marked for motor nerve fibers. ${ }^{[10,15,18]}$

In our series, the clinical symptoms in 113 patients have been of longer duration before any evident sensory-motor damage occurred. These symptomatic patients showing only positive phenomena take longer to get clinically manifest damage. Surprisingly NCV were similar to that of the PB group having < six months involvement with symptoms.

It was interesting to note that the conduction velocities never reached zero i.e., some conduction continued to occur even in cases which showed no response on clinical testing for sensory-motor functions. It might be due to discharges from regenerating nerve fibers. ${ }^{[19]}$ Such velocities could not be explained by volume conduction alone. Probably some fibers survive long enough to conduct. Several workers have demonstrated healthy nerve fibers within anesthetic areas ${ }^{[16]}$ in tissue sections.

The absence of detectable potential from areas showing complete loss of sensation may mean absence of myelinated fibers and failure of the surviving fibers to be stimulated due to increased thresholds or a complete dispersion of waves. Even in the absence of sensations, action potentials could be recorded from nerve fibers supplying the area concerned. Therefore it is certain that sufficient fibers in the myelinated group survived to account for the presence of these potentials. ${ }^{[6]}$ 
The sensory potentials obtained from leprosy patients were of much smaller amplitude and the typical biphasic character seen in normal persons was absent in leprosy patients. The thresholds of the fibers were also considerably raised, probably as a result of thickening of the sheath.

In early cases where damage is more in slow conducting fibers (average velocity fibers) the change in conduction velocity may not be marked, and calls for the measurement of fast fibers separately because potentials recorded are mainly from myelinated fibers. ${ }^{[6]}$

Patients with known leprosy having normal clinical picture and abnormally slow conduction at the elbow may be an early sign of nerve involvement thus being of some prognostic value. With these findings therapy may be initiated for the nerve inflammation prior to the time when the patient becomes disabled which at times is sudden in onset. Such patients will be very few and can easily be monitored.

From our observations it is apparent that leprosy patients may show a gradual insidious deterioration of function in the affected peripheral nerve trunk. This indicates that probably the peripheral nerve is subjected to increasing pressures with resultant hypoxia from the presence of even a few adhesions. ${ }^{[20]}$

It is difficult to decide whether or not a clinically enlarged nerve in a patient is necessarily at risk. If the nerve is enlarged but has normal electrophysiological functions, a further period of observation is indicated. However, in a field situation this may not hold good when periodic evaluation is not feasible for various reasons.

It is said that latency changes occur much earlier than amplitude or conduction velocity changes in compression neuropathies. ${ }^{[21]}$ Leprosy being a mixed neuropathy such presentations were not seen because compression occurs rather late in leprosy in comparison to inflammatory demyelination. Study of wave forms and action potentials might prove to be better indicators of early neural damage. Such studies are needed in cases selected from the field because patients usually report to the hospital only when the nerve damage becomes clinically manifest.

\section{References}

1. Hackett ER, Shipley DE, Livengood R. Motor nerve conduction velocity studies of ulnar nerve in patients with leprosy. Int J Lepr $1968 ; 36: 282-7$

2. Campion D. Electrodiagnostic testing in Hand Surgery. J Hand
Surg 1996;21:947-56

3. Verghese M, Ittimani KV, Satyanarayan KR, Mathai R, Bhakthaviziam C. A study of the conduction velocity of the motor fibers of ulnar and median nerves in leprosy. Int J Lepr Other Mycobact Dis 1970;38:271-7.

4. MeLeod JG, Hargrave JC, Walsh JC, Booth GC, Gye RS, Barron A. Nerve conduction studies in leprosy. Int J Lepr Other Mycobact Dis $1975 ; 43: 21-31$.

5. Singh T, Kaur S, Kumar B, Sawhnoy BB, Chopra JS. A study of motor and sensory nerve conduction in leprosy. Indian J Med Res 1977;65:632-9.

6. Dash MS. A study of the conduction velocity of sensory fibres of the ulnar nerve in leprosy. Int J Lepr 1967;35:460-9.

7. Brown TR, Kovindha A, Wathanadilokkol U, Piefer A, Smith T, Kraft GH. Leprosy neuropathy: Correlation of clinical and eletrophysiological tests. Indian J Lepr 1996;68:1-14.

8. Ramkrishnan AG, Srinivasan TM. Electrophysiological correlates of Hanseniasis. Int J Lepr 1995;63:395-408.

9. Rao SP, Bharambe MS. Electrophysiological studies in early tuberculoid leprosy. Indian J Lepr 1993;65:181-7.

10. Samant G, Shetty VP, Uplekar MW, Antia NH. Clinical and electrophysiological evaluation of nerve function impairment, following cessation of multidrug therapy in leprosy. Lepr Rev 1999; 70:10-20.

11. Ramadan W, Mourad B, Fadel W, Ghoraha E. Clinical, electrophysiological and immunological study of peripheral nerves in Hansen's disease. Lepr Rev 2001;72:35-49.

12. Government of India Guidelines on Modified MDT. Government of India Leprosy Division, Directorate General of Health Service Ministry of Health and Family Welfare: New Delhi, India; 1994.

13. Antic NH, Mehta L, Shetty V Irani FF. Clinical, electrophysiological, quantitative histologic and ultra-structural studies of the index branch of the radial nerve in leprosy I. Preliminary Report. Int J Lepr 1975;43:106-13.

14. Antic NH, Pandya SS, Dastur DK. Nerves in the arm in leprosy I Clinical, Electrodiagnostic and operative aspects. Int J Lepr 1970;38:12-29.

15. Donde SV, Shah A, Antia NH. Nerve conduction in leprosy: In vivo and In vitro study. Lepr India 1983;55:12-21.

16. Jayaraj AP, Chaudhury DS. Epithelial and sub-epitlielial innervation in lepromatous, leprosy. Lepr India 1960;32:167-9.

17. Marquees W, Barreira AA. Normal median near nerve potential. Bras J Pled Biol Ryas 1997;30:1431-5.

18. Pandya NJ. Surgical decompression of nerves in leprosy. An attempt at prevention of deformities. A clinical, electrophysiologic, histopathologic and surgical study. Int J Lepr 1978;46:47-55.

19. Marques W, Norma T, Foss MD, Arruda AP, Barreira AA. Near nerve potential in lepromatous leprosy. Muscle Nerve 2003;28:460-3.

20. Magora A, Sheskin J, Sagher F, Gonen B. The condition of the peripheral nerve in leprosy under various forms of treatment. Conduction velocity studies in long-term follow-up. Int J Lepr 1970;38:12-29.

21. Kupfer DM, Bronson J, Gilbert WL, Beck J, Gillet J. Differential latency testing: A more sensitive test for radial tunnel syndrome. J Hand Surg 1998;23:859-64.

Accepted on 23-11-2006

Source of Support: Nil, Conflict of Interest: None declared. 